\title{
Effectiveness of water-saving technologies during early stages of restoration of endemic Opuntia cacti in the Galápagos Islands, Ecuador
}

\author{
Patricia I Tapia ${ }^{\text {Equal first author, } 1}$, Luka Negoita ${ }^{\text {Equal first author, } 2}{ }^{2}$, James P Gibbs ${ }^{3}$, Patricia Jaramillo ${ }^{\text {Corresp. 2, } 4}$ \\ ${ }^{1}$ School of Natural and Environmental Sciences, Newcastle University, Newcastle Upon Tyne, Tyne and Wear, United Kingdom \\ 2 Charles Darwin Research Station, Galápagos Verde 2050, Charles Darwin Foundation, Santa Cruz, Galápagos, Ecuador \\ 3 Department of Environmental and Forest Biology, State University of New York, Syracuse, New York, United States \\ 4 Facultad de Ciencias, Universidad de Málaga, Málaga, Spain \\ Corresponding Author: Patricia Jaramillo \\ Email address: patricia.jaramillo@fcdarwin.org.ec
}

Restoration of keystone species is a primary strategy used to combat biodiversity loss and recover ecological services. This is particularly true for oceanic islands, which despite their small land mass, host a large fraction of the planet's imperiled species. The endemic Opuntia spp. cacti are one example and a major focus for restoration in the Galápagos archipelago, Ecuador. These cacti are keystone species that support much of the unique vertebrate animal community in arid zones, yet human activities have substantially reduced Opuntia populations. Extreme aridity poses an obstacle for quickly restoring Opuntia populations though water-saving technologies may provide a solution. The aim of this study was to evaluate current restoration efforts and the utility of two water-saving technologies as tools for the early stages of restoring Opuntia populations in the Galápagos archipelago. We planted 1425 seedlings between 2013 and 2018, of which 66\% had survived by the end of 2018. Compared with no-technology controls, seedlings planted with Groasis Waterboxx ${ }^{\circledR}$ water-saving technology (polypropylene trays with water reservoir and protective refuge for germinants) had a greater rate of survival in their first two-years of growth on one island (Plaza Sur) and greater growth rate on four islands whereas the "Cocoon" water-saving technology (similar technology but made of biodegradable fiber) did not affect growth and actually reduced seedling survival. Survival and growth rate were also influenced by vegetation zone, elevation, and precipitation in ways largely contingent on island. Overall, our findings suggest that water-saving technologies are not always universally applicable but can substantially increase the survival and growth rate of seedlings in certain conditions, providing in some circumstances a useful tool for improving restoration outcomes for rare plants of arid ecosystems. 


\section{Effectiveness of water-saving technologies during early stages of restoration of endemic}

2 Opuntia cacti in the Galápagos Islands, Ecuador

5 Patricia Isabela Tapia ${ }^{1}$, Luka Negoita ${ }^{2}$, James P Gibbs ${ }^{3}$, and Patricia Jaramillo ${ }^{2,4}$

$7{ }^{1}$ School of Natural and Environmental Sciences, Newcastle University, Newcastle Upon Tyne,

8 Tyne and Wear, United Kingdom

92 Galápagos Verde 2050, Charles Darwin Research Station, Charles Darwin Foundation, Santa

10 Cruz, Galápagos, Ecuador

$11{ }^{3}$ Department of Environmental and Forest Biology, State University of New York, Syracuse,

12 NY, USA

$13 \quad{ }^{4}$ Facultad de Ciencias, Universidad de Málaga, Málaga, España

15 Corresponding Author:

16 Patricia Jaramillo 2,4

17 Charles Darwin Research Station, Charles Darwin Foundation, Santa Cruz, Galápagos, Ecuador

Email address: patricia.jaramillo@fcdarwin.org.ec

\section{Abstract}

Restoration of keystone species is a primary strategy used to combat biodiversity loss and recover ecological services. This is particularly true for oceanic islands, which despite their small land mass, host a large fraction of the planet's imperiled species. The endemic Opuntia spp. cacti are one example and a major focus for restoration in the Galápagos archipelago, Ecuador. These cacti are keystone species that support much of the unique vertebrate animal community in arid zones, yet human activities have substantially reduced Opuntia populations. Extreme aridity poses an obstacle for quickly restoring Opuntia populations though water-saving technologies may provide a solution. The aim of this study was to evaluate current restoration efforts and the utility of two water-saving technologies as tools for the early stages of restoring Opuntia 
32 which $66 \%$ had survived by the end of 2018. Compared with no-technology controls, seedlings

33 planted with Groasis Waterboxx ${ }^{\circledR}$ water-saving technology (polypropylene trays with water

34 reservoir and protective refuge for germinants) had a greater rate of survival in their first two-

35 years of growth on one island (Plaza Sur) and greater growth rate on four islands whereas the

36 "Cocoon" water-saving technology (similar technology but made of biodegradable fiber) did not

37 affect growth and actually reduced seedling survival. Survival and growth rate were also

38 influenced by vegetation zone, elevation, and precipitation in ways largely contingent on island.

39 Overall, our findings suggest that water-saving technologies are not always universally

applicable but can substantially increase the survival and growth rate of seedlings in certain

conditions, providing in some circumstances a useful tool for improving restoration outcomes for rare plants of arid ecosystems.

\section{Introduction}

The restoration of previously abundant keystone species is one way to combat loss of biodiversity and ecological services (Grime, 1998). This is particularly true on oceanic islands, which comprise little of the planet's land mass yet host a disproportionate amount of its imperiled species (Myers et al., 2000; Campbell \& Donlan, 2005). The Galápagos archipelago is a case in point: its land area is minimal $\left(8006 \mathrm{~km}^{2}\right)$ yet it hosts a remarkable array of endemic life forms with as many as $60 \%$ of its 168 endemic plant species now threatened with extinction (Black, 1973; Tye, 2007). Active restoration programs are underway throughout the archipelago. For example, Project Isabela (1997-2006), was the world's largest restoration effort at the time and dedicated to eradicating introduced mammal herbivores on multiple islands in the archipelago (Cruz et al., 2009; Carrion et al., 2011).

The Opuntia spp. cacti (prickly pear cactus) are a major focus for restoration in the Galápagos archipelago, Ecuador, which hosts six endemic species, with 14 total taxa when including varieties. Human impact in the Galápagos archipelago has steadily increased over the last 200 years (Jaramillo, 1998), resulting in declines of Opuntia populations on these islands

60 (Snell, Snell \& Stone, 1994). Several factors have been attributed as the primary threats to

61 Opuntias including herbivory by introduced mammals (Grant \& Grant, 1989), extinction of

62 keystone predators that once regulated numbers of cactivores (Sulloway \& Noonan, 2015), and 
63 the increased intensity of El Niño events likely driven by climate change (Snell, Snell \& Stone, 64 1994; Hicks \& Mauchamp, 1996). Opuntia cacti provide many ecosystem services for other

65

66

67

68 native and endemic species (Grant \& Grant, 1981; Hicks \& Mauchamp, 1995, 1996; Gibbs, Marquez \& Sterling, 2008). Examples include Galápagos giant tortoises and land iguanas that depend on Opuntia cacti as a food source while also contributing to Opuntia regeneration through seed dispersal (Hamann, 1993; Snell, Snell \& Stone, 1994; Gibbs, Marquez \& Sterling, 2008; Gibbs, Sterling \& Zabala, 2010). Efforts are being made to protect and restore populations of these imperiled cacti (Hicks \& Mauchamp, 1996) but it is not clear which factors most control Opuntia populations (Sulloway \& Noonan, 2015). Opuntia declines on Plaza Sur Island, for example, are especially pronounced (60\% reduction since 1957$)$ despite the eradication of introduced goats since the populations are likely too low to successfully regenerate in the presence of native herbivory (Grant \& Grant, 1989; Snell, Snell \& Stone, 1994; Sulloway \& Noonan, 2015).

Severe aridity poses an obstacle for restoring plant communities over much of Galápagos due to the inherently slower growth and low germination of plants growing in these conditions, including xerophytes such as Opuntia cacti (Hicks \& Mauchamp, 1996). The lowland zones of the archipelago, where Opuntias are most common and historically abundant (e.g., Snell, Snell \& Stone, 1994; Hicks \& Mauchamp, 1996; Browne et al., 2003), can receive less than $10 \mathrm{~cm}$ rainfall annually (Trueman \& d'Ozouville, 2010). Though these conditions are normal, they increase the time it would take for small populations of Opuntias to return to historic sizes (Grant \& Grant, 1989; Helsen et al., 2009). Rapid restoration through active planting of these species is critical for reducing the risk of extinction until their threats are better understood and before other threats such as invasive plant species make it more difficult or impossible for Opuntias to naturally regenerate (Mauchamp et al., 1998; Helsen et al., 2009). "Water-saving” technologies are tools that may help increase survival and growth of planted cactus seedlings while reducing the need for manual watering and speeding the restoration process (Kulkarni, 2011; Hoff, 2014; Jaramillo et al., 2014; Jaramillo, 2015; Jaramillo et al., 2015; Faruqi et al., 2018; Jaramillo, Tapia, \& Gibbs, 2018; Peyrusson, 2018, 2018). The Groasis Waterboxx ${ }^{\circledR}$ (Groasis) and biodegradable Cocoon system are two relatively inexpensive water-saving technologies that can be easily implemented during the planting process (Appendix 1). These technologies function by holding water in basins that surround the young plant and feed water to the soil at a slow but 
94 constant rate through capillary action via a short length of rope that connects the basin to the soil.

95 Aside from the physical design differences that influence where the plant is relative to soil 96 surface and biodegradability, the main difference in these technologies is that Groasis actively

97 collects dew and rainwater, while the Cocoon technology is only filled with water once at the 98 time of planting (Appendix 1). Although these particular technologies show much promise 99 through anecdotal evidence and reports, there remains a dearth in formal scientific studies 100 evaluating their efficacy (but see Liu, Li, \& Ren, 2014). Therefore, the objective of the current 101 study was to evaluate current restoration efforts and test the utility of two water-saving 102 technologies as tools for restoring Opuntia populations in the Galápagos archipelago. Through

103 this objective we hope to better understand the utility of water-saving technologies for restoring

104 these and other keystone plant species in arid island ecosystems throughout the world.

105

106

Materials \& Methods

108

Study Area, Focal Species, and Water-saving Technologies

109

The Galápagos archipelago is located in the Pacific Ocean, about $1000 \mathrm{~km}$ west of the coast of mainland Ecuador $\left(1^{\circ} 39^{\prime} \mathrm{N}, 92^{\circ} 0^{\prime} \mathrm{W}\right.$ to $1^{\circ} 26^{\prime} \mathrm{S}, 89^{\circ} 14^{\prime} \mathrm{W}$, WGS 84, Fig. 1) (DPNG, 2014). Our study focused on measuring the utility of water-saving technologies for enhancing cactus growth and survival of four endemic Opuntia taxa within the archipelago: Opuntia echios var. echios Howell, Opuntia echios var. gigantea Howell, Opuntia megasperma var. megasperma Howell, and Opuntia megasperma var. orientalis Howell (Hicks \& Mauchamp, 1996). We evaluated two technologies: Groasis Waterboxx ${ }^{\circledR}$ (Groasis), a protective polypropylene box that collects rainwater that it provides to the plant (Hoff, 2014); and the Cocoon system, a 99\% biodegradable box that contains and provides water to the plant similar to

118 Faruqi et al., 2018; Appendix 1). These water-saving technologies have been proposed as a tool

119 to assist plant restoration of Opuntia taxa via “Galápagos Verde 2050” (GV2050), a project

120 started by the Charles Darwin Foundation in 2013 with the mission of restoring degraded

121 ecosystems and aiding with sustainable agriculture in the Galápagos archipelago (Jaramillo et al.,

$1222014,2015,2017)$. GV2050 seeks to restore ecosystems by using a data-informed experimental

123 approach for understanding the best conditions, methods, and tools for successful plantings of

124 native and endemic species (Jaramillo et al., 2015). 


\section{Planting and Data Collection}

A total of 1425 cacti (1137 Opuntia echios var. echios, 68 Opuntia echios var. gigantea,

24 Opuntia megasperma var. megasperma, and 196 Opuntia megasperma var. orientalis) were planted on six islands (Baltra, Española, Floreana, Plaza Sur, San Cristóbal, and Santa Cruz) between 2013 and 2018 (Table 1). Permission to plant Opuntias within protected sites on these islands was granted by the Dirección del Parque Nacional Galápagos (DPNG) through permit number PC-11-19 (Table 2). To evaluate the factors most important for successful Opuntia restoration, data were used only from Opuntias that were grown from seed and planted using either Groasis, Cocoon, or control (no technology) treatments on Floreana, Santa Cruz, Baltra, and Plaza Sur islands yielding a sample of 1029 Opuntia individuals of three taxa (Table 1).

Planting sites on each island were selected based on locations where historic Opuntia

137 populations were known to have thrived but are now in decline (Hicks \& Mauchamp, 1996; Sulloway et al., 2013; Sulloway \& Noonan, 2015; Table 2). For example, since 1957 the Opuntia population on Plaza Sur Island has had an overall mortality of more than $60 \%$ and at Cerro Dragon on Santa Cruz Island there has been an overall loss of 78\% (Sulloway \& Noonan, 2015). Seedlings were planted from seeds collected in each respective planting location using standardized seed collection and stratification techniques and grown for one year at the Charles Darwin Research Station, Santa Cruz Island, before transferring to each site on each island

144 (Jaramillo, Tapia \& Gibbs, 2017; Jaramillo, 2019, Table 2). Each seedling was randomly assigned a treatment of either control (no technology), Groasis, or Cocoon, ensuring an adequate sample of replicates within each treatment and site. The number of controls was maintained at one control for every five technology treatment replicates. A greater proportion of Groasis replicates were used because the overarching goal of this work is to successfully restore populations of Opuntias and current anecdotal evidence and observations suggest this technology

150 provides the greater benefit for achieving this. The uneven design does not impact our analyses or interpretation of results since we ensured a relatively adequate number of controls within each

152 island. In total, 823 Groasis, 38 Cocoons, and 168 controls were used in the analysis. Planting 153 locations for each seedling were determined haphazardly in the field at each site using the basic 154 criteria that a seedling could be physically planted while not being in direct competition with other plants (i.e., the substrate was soil rather than rock and free of overarching vegetation that 
156 would shade the seedling). Truly random selection of specific planting locations was impractical

157 due to the large heterogeneity of exposed bedrock and competing vegetation, so locations were

158 often chosen opportunistically. Though planting locations were not random, treatment

159 assignment was random and thus our methodology does not interfere with our primary goal of

160 evaluating the use of water-saving technologies. Plantings were conducted according to

161 established methods for installing Groasis, Cocoon, and controls (Jaramillo, 2019). Wire fences

162 were secured and maintained around each individual planting on Plaza Sur, Baltra, and Española

163 islands to prevent herbivory from land iguanas or giant tortoises present on those islands but

164 absent from other islands where Opuntias were planted. Planting site co-variates were recorded

165 at time of planting: elevation, soil type (rocky-sand, rocky-clay, rich-clay, rich, sandy, and clay),

166 vegetation zone (arid, littoral, and transitional; Johnson \& Raven, 1973), and treatment (control,

167 Groasis, and Cocoon). Growth (vegetative height) and qualitative plant state ("good," "regular,"

168 "poor," and "dead") were noted during each repeated visit approximately every six weeks

169 following planting. Aside from "dead" which was non-arbitrary and easy to identify, the other

170 states were based on the subjective relative appearance of the plant (i.e., degree of desiccation or

171 browning of cladodes). Though these assignments were not objective, they were not used for our

172 analysis and simply provide a quick way to gauge the relative state of the plants.

173 Two-year survival and growth rate of seedlings were used to evaluate restoration success

174 (Menendez \& Jaramillo, 2015). Two-year survival was quantified as whether or not a seedling

175 survived for at least two years after planting - the period of greatest mortality risk (we found

$17679 \%$ survival in the first year and $86 \%$ survival in the second year, compared with $99 \%$ survival

177 in the third year). For this analysis, only plants that had the potential to grow and survive for two

178 years were included. However, while the analysis was based on seedlings planted up until 2019,

179 additional monitoring data from those plants until September 2019 allowed us to increase the

180 sample of plants for which we could model two-year survival. Relative growth rate was

181 calculated based on the vegetative height of each seedling over time. Whereas survival is the

182 primary metric for establishing success of population restoration, growth rate can indicate the

183 speed of ecosystem recovery due to the rate of increase in the biomass of a keystone species

184 (Grime, 1998), and may also shorten the time to reproductive maturity in Opuntias (Racine \&

185 Downhower, 1974). An additional environmental covariate of total precipitation across the six 
186 months following planting was compiled based on available climate data from 2013 to 2019

187 (Trueman \& D’Ozouville, 2010; CDF, 2018).

188

189 Data analysis

190 All statistical analyses were conducted using the R statistical software package v3.3.3 (R Core

191 Team, 2017). To test the overall effect of water-saving technologies on the restoration of

192 Opuntia cacti, a model comparison approach was implemented using fixed- and mixed-effects

193 regression models of the form:

194

195

196

2-year survival logistic fixed-effect model:

2YearSurvival

$$
\begin{aligned}
& =\alpha+\beta_{1} \times \text { treatment }+\beta_{2} \times 6 \text { MonthPrecip }+\beta_{3} \times \text { Zone }+\beta_{4} \times \text { elevation } \\
& +\beta_{5} \times \text { island }
\end{aligned}
$$

\section{Relative growth rate linear mixed-effect model:}

$$
\log (R G R)
$$

$$
\begin{aligned}
& =\alpha+\beta_{1} \times \text { treatment }+\beta_{2} \times 6 \text { MonthPrecip }+\beta_{3} \times \text { SoilType }+\beta_{4} \times \text { Zone }+ \\
& \beta_{5} \times \text { elevation }+\beta_{6} \times \text { PlantAge }+\beta_{6} \times \text { island }+N\left(0, \sigma_{\text {PlantID }}^{2}\right)
\end{aligned}
$$

200

201

The growth rate model is a general linear mixed-effects regression fit using the 'lme4' package (Bates et al., 2015). Relative growth rate (RGR) was calculated as the relative rate of increase in height over time and was log-transformed to meet assumptions of normality. Growth rates of zero were excluded from this analysis to maintain normality. Plant age was included in the model to account for the fact that RGR changes as seedlings get older. Plant ID is included as a random effect. Random effects account for within-group correlation that results from non-independent data points (Pinheiro \& Bates, 2000). For example, our growth data are based on repeated measures of each individual plant, which means that growth measurements are not independent within an individual plant. The random effect for Plant ID allows us to include all observations

210 in our analysis by accounting for this non-independence. The two-year survival model tested the 211 overall survival of each seedling two years after planting and was fit using a generalized linear 212 model function with a binomial family logit function in the 'base' package (R Core Team, 2017). 213 Because only one data point was available for each plant, the lower sample size required a 
214 simpler model in which soil type was removed in order to allow the model to converge

215 successfully and no random effects were necessary. These models were then compared to null

216 models using the likelihood-ratio to test for the effect of treatment on growth rate and survival.

217 Null models were the same as the models listed above except for the exclusion of technology

218 treatment. A significant difference between the two models indicates that the variable that was

219 excluded (i.e., treatment) is a significantly important predictor.

220 We examined the relative effect of each variable within the growth rate and survival

221 models to assess the relative importance of technologies as well as other environmental factors

222 such as soil type and elevation. All continuous variables in our models were standardized by

223 subtracting the mean and dividing by two times the standard deviation in order to relativize the

224 effect of each variable coefficient on growth rate and two-year survival (Gelman, 2008).

225 Confidence intervals (95\%) for each coefficient in each full model were then generated through

226 the "profile" method (Stryhn \& Christensen, 2003) and plotted for visual comparison. P-values

227 were generated for each coefficient in the logistic regression based on the Wald statistic. For the

228 mixed effect growth rate model, P-values were generated using the Satterthwaite method in the

229 'ImerTest' package in R (Kuznetsova et al., 2017). P-values generated from mixed-effect models

230 are not always accurate, but we include these values for the sake of highlighting the degree to

231 which variables differ in their relative importance. Furthermore, all significance values generated

232 in this way were consistent with confidence interval results. Coefficients for logistic models were

233 back-transformed to odds ratio by exponentiating and subtracting one. In this way the coefficient

234 values can be interpreted as the proportional effect of each variable on increasing (or decreasing

235 if negative) the probability of two-year survival. Each model was fit using data from all four

236 islands included in the analysis (Baltra, Floreana, Santa Cruz, and Plaza Sur), but due to high

237 control treatment mortality on Plaza Sur, the models were also tested using data that excluded

238 Plaza Sur as well as using data exclusively from Plaza Sur. Continuous variables were

239 standardized within each of these three analyses. When testing with data exclusively from Plaza

240 Sur, "island" was removed from the models and treatment type consisted of only Groasis and

241 controls because no Cocoons were used on Plaza Sur. Finally, the current state of all planted

242 individuals included in the analysis (up through 2018) was plotted as stacked bar plots to

243 visualize rates of survival between islands and treatments. 


\section{Results}

246

\section{General outcomes}

248 Of the 1425 Opuntia spp. individuals planted between 2013 and 2018, (most plantings were 249 made in 2015 and 2016, Fig. 2), 943 Opuntias remained alive by the end of 2018 (66\% overall

250 survival, Fig. 2). Of those individuals planted at least three years prior to 2019, Opuntia mortality 251 three years after planting fell to $1 \%$ and overall survival leveled at 67\%. On Plaza Sur, 737 252 Opuntia individuals were planted between 2015 and 2018 with 452 survivors by the end of 2018 253 (an increase of 106\% from the last recorded population estimates of 426 in 2014 (Jaramillo, 254 Tapia \& Gibbs, 2017)). Survival of seedling plantings on Plaza Sur was $26.8 \%(n=82)$ for 255 controls and 62.2\% $(n=519)$ for Groasis (Fig. 3a). Survival of seedling plantings on Floreana 256 was $66.7 \%(n=3)$ for controls and 31.2\% $(n=16)$ for Groasis (Fig. 3b). Survival of seedling 257 plantings on Baltra was 79.7\% $(n=74)$ for controls, $45 \%(n=20)$ for Cocoon, and 65.5\% $(n=$ 258 255) for Groasis (Fig. 3c). Survival of seedlings planted on Santa Cruz was 77.8\% $(n=9)$ for 259 controls, 27.8\% $(n=18)$ for Cocoon, and 72.7\% $(n=33)$ for Groasis (Fig. 3d).

260

261 Outcomes across all islands

262 Treatment type (Groasis, Cocoon, or Control) was associated with growth rate $\left(\chi^{2}(2)=54.54, \mathrm{P}\right.$ $263<0.001)$ and two-year survival rate of Opuntia seedlings $\left(\chi^{2}(2)=41.53, \mathrm{P}<0.001\right)$. In the two264 year survival logistic regression, elevation $(1.88, \mathrm{P}=0.001)$ and littoral zone $(13.72, \mathrm{P}<0.001)$ 265 had odds ratios with confidence intervals that did not overlap zero (Fig. 4a). Groasis technology 266 had a positive odds ratio of $1.28(\mathrm{P}<0.001)$, while Cocoon had a negative odds ratio of $-0.89(\mathrm{P}$ $267<0.001)$ (Fig. 4a). In the growth rate regression, littoral zone (0.48, $\mathrm{P}<0.001)$, plant age $(-0.51$, $268 \mathrm{P}<0.001)$, rocky-sand soil $(-0.3, \mathrm{P}=0.026)$, and six-month precipitation $(0.23, \mathrm{P}=0.033)$ all 269 had effect sizes with confidence intervals that did not overlap zero (Fig. 4b). Groasis technology 270 had a positive effect size with a coefficient of $0.52(\mathrm{P}<0.001)$, while Cocoon had an 271 insignificant coefficient $(\mathrm{P}=0.179)$ (Fig. 4b).

272

273 Outcomes on Plaza Sur Island only

274 On Plaza Sur Island, treatment type (Groasis or Control) was associated with growth rate of 275 Opuntia species $\left(\chi^{2}(1)=18.92, \mathrm{P}=0.001\right)$ and two-year survival rate of Opuntia seedlings $\left(\chi^{2}\right.$ 
$276(1)=23.44, \mathrm{P}<0.001)$. In the two-year survival logistic regression, littoral zone $(379.63, \mathrm{P}<$ 277 0.001), elevation (1.54, $\mathrm{P}<0.001)$, and six-month precipitation $(-0.67, \mathrm{P}<0.001)$ had odds 278 ratios with confidence intervals that did not overlap zero (Fig. 4c). Groasis technology had a 279 positive odds ratio of $3.7(\mathrm{P}<0.001)$ (Fig. 4c). In the growth rate regression, littoral zone $(0.49$, $280 \mathrm{P}<0.001)$, plant age $(-0.26, \mathrm{P}<0.001)$, six-month precipitation $(-0.23, \mathrm{P}=0.001)$, and elevation $281(0.17, \mathrm{P}=0.012)$ all had effect sizes with confidence intervals that did not overlap zero (Fig. 4d).

282 Groasis technology had a positive effect size with a coefficient of $0.46(\mathrm{P}<0.001)$ (Fig. 4d).

283

284 Outcomes on all islands excluding Plaza Sur

285 Treatment type (Groasis, Cocoon, or Control) was associated with growth rate of Opuntia 286 species $\left(\chi^{2}(2)=17.8, \mathrm{P}<0.001\right)$, but not with two-year survival rate of Opuntia seedlings $\left(\chi^{2}(2)\right.$ $287=1.85, \mathrm{P}=0.397)$. In the two-year survival logistic regression, transition zone $(-0.99, \mathrm{P}<0.001)$ 288 and littoral zone $(-0.77, \mathrm{P}=0.013)$ had negative odds ratios with confidence intervals that did not 289 overlap zero (Fig. 4e). Both Groasis and Cocoon technologies had insignificant negative odds 290 ratios of $(\mathrm{P}=0.236)$ and $(\mathrm{P}=0.305)$ respectively (Fig. 4e). In the growth rate regression, plant 291 age $(-0.83, \mathrm{P}<0.001)$, six-month precipitation $(0.52, \mathrm{P}<0.001)$, and rocky-clay soil $(-0.23, \mathrm{P}=$ 292 0.032) had effect sizes with confidence intervals that did not overlap zero (Fig. 4f). Groasis 293 technology had a positive effect size with a coefficient of $0.4(\mathrm{P}<0.001)$, while cocoon had an 294 insignificant coefficient $(\mathrm{P}=0.261)$ (Fig. 4f).

295

296

\section{Discussion}

297

Water-saving technologies enhanced survival and growth of Opuntia plantings, but benefits of these technologies were highly contingent upon planting environment. For example, Groasis technology was effective at increasing growth rate across islands overall, but was only effective at aiding survival on Plaza Sur Island where Groasis increased the probability of twoyear survival of seedlings more than three-fold (370\%) (Fig. 4). Cocoon technology, however, provided no improvement in growth rate and actually reduced probability of two-year survival of seedlings by $89 \%$ overall (Fig. 4). Although still in its early stages with all planted Opuntias yet to reach maturity, our restoration efforts have increased the population of Opuntia spp. in the Galápagos archipelago by 943 individuals (66\% survival of 1425 plantings), more than doubling 
306 the population of Opuntia cacti on Plaza Sur Island, from 426 to 878 in just four years

307 (Jaramillo, Tapia \& Gibbs, 2017).

308 These results emphasize the species- and site-specific contingencies of applying water-

309 saving technologies for plant restorations. For example, Cocoon technology did not provide any

310 advantage when planting Opuntias in the Galápagos archipelago. This is despite the fact that in

311 other systems and with other species Cocoon has been shown to increase survival rates in planted

312 trees from $0-20 \%$ to $75-95 \%$ (Faruqi et al., 2018). One possible explanation is that Opuntia cacti

313 have a short initial rooting depth compared to other species (Snyman, 2005), and this may reduce

314 access to the water available from the Cocoon (Land Life Company, 2015; Appendix 1). Acacia

315 macracantha, for example, has much deeper roots and has had much greater success when

316 planted with Cocoon technology in the Galápagos (GV2050, unpublished data).

317 Although Groasis technology helped increase growth rate of Opuntias overall, it had a

318 clear, positive effect on the survival of Opuntias only on Plaza Sur Island. A likely factor

319 contributing to this is that compared to other islands, the majority of Opuntias were planted on

320 Plaza Sur preceding the greatest period of drought in the Galápagos over the last five years

321 (Appendix 2; CDF, 2018). Despite fairly regular seasonal patterns of water availability in the

322 Galápagos (Snell \& Rea, 1999; Restrepo et al., 2012), there remains much variability, especially

323 caused by El Niño events (Trueman \& d'Ozouville, 2010). In this way Groasis may have the

324 greatest advantage when ensuring water availability for Opuntias during periods of especially

325 severe drought, and in particular for seedlings which rely on periods of greater moisture to

326 germinate and survive (Hicks \& Mauchamp, 1996). Opuntia cacti are typically more resistant to

327 desiccation and water stress compared to other species that do not have physiological adaptations

328 for surviving low-water desert conditions (Racine \& Downhower, 1974; Dubrovsky, 1998), and

329 this may explain why Groasis was only effective for Opuntia cacti under extreme drought. These

330 findings support the idea that water availability for Opuntias plays less of a role in survival than

331 previously assumed (Racine \& Downhower, 1974; Coronel, 2002; Jaramillo, Tapia \& Gibbs,

332 2018). These findings do not negate the value of the Cocoon or Groasis technology for

333 restoration overall, but rather presents the important observation that water-saving technologies

334 such as Cocoon and Groasis should be considered on a case-by-case basis and tested with each

335 species and in different environmental conditions before making expansive planting efforts.

336 Groasis technology may provide a form of insurance for the unpredictability of extreme drought 
337 events and the benefits of using Groasis technology may in some cases outweigh the costs in the

338 long run (e.g., 22 USD per Groasis unit plus overhead and installation time (Groasis $\left.{ }^{\circledR}, 2019\right)$ ).

339 Site co-variates also affected Opuntia survival and growth. In particular, vegetation zone,

340 elevation, and precipitation were important predictors of Opuntia survival and growth but as with

341 water-saving technologies, these effects were highly contingent on island. Opuntias had a greater

342 survival and growth rate in the littoral vegetation zone on Plaza Sur but had greater survival in

343 the arid vegetation zone on other islands. This effect may be due to an interaction between

344 environmental and biotic factors unique to Plaza Sur or other islands. For example, Plaza Sur has

345 especially high land iguana densities speculated to be due to the loss of its main predator from

346 the island, the Galápagos hawk (Sulloway \& Noonan, 2015). This high herbivore density may

347 help keep invasive plant species in check on Plaza Sur-species that may otherwise shade out

348 Opuntia seedlings on other islands (Schofield, 1973, Hicks \& Mauchamp, 1996, 2000).

349 Surprisingly, the level of precipitation six-months after planting did not increase seedling

350 survival, and actually decreased survival of seedlings planted on Plaza Sur. This finding

351 contradicts conclusions from previous work by Coronel (2002) who found that precipitation

352 during the six months following planting increased Opuntia survival. Coronel (2002), however,

353 found that the positive effect of rainfall following planting was mostly evident in Opuntias

354 grown from vegetative cladodes rather than seeds as in the current analysis. Furthermore, most

355 seedlings were planted on Plaza Sur at the start of a long period of drought so there was not as

356 much variation in precipitation on Plaza Sur seedlings to fully test its effects. Elevation was only

357 a significant predictor of survival and growth rate on Plaza Sur (Fig. 4). This may be in part

358 because although littoral zone on Plaza Sur has a positive impact on survival and growth,

359 seedlings that are too low in elevation are more exposed to ocean salt spray which can increase

360 seedling mortality (Boyce, 1954). Soil type had only marginally significant effects on growth

361 rate (Fig. 4), suggesting that, at least for Opuntias, substrate is of less importance for growth rate

362 than factors such as vegetation zone or elevation. The effect of soil type on survival could not be

363 tested with the current data due to limitations in sample size.

364 The observational aspects of our study have some inherent limits. Although it seems

365 likely that extreme drought was the primary driver of control treatment seedling mortality on

366 Plaza Sur, other effects cannot be ruled out. Plaza Sur is a small island (the smallest island by far

367 of the four in this analysis: only 13 ha, with the next larger being Baltra at 2100 ha), which could 
368 increase the exposure of seedlings to salt spray, exposure to sea lion activity, as well as a suite of 369 other effects associated with small islands (Lomolino \& Weiser, 2001). It may also be that the 370 high concentration of land iguanas and sea lions (P. Jaramillo, 2018, pers. obs.) has impacted the 371 edaphic environment of the island through their excrement as can be common on seabird islands 372 (Rajakaruna et al., 2009). Thus, the small area and low variation in elevation, precipitation, and 373 vegetation zones associated with Plaza Sur plantings suggests that any significant effect of these

374 factors within Plaza Sur be taken cautiously when generalizing to Opuntia restoration beyond

375 this island. The experimental treatments of the study involving water-saving technologies,

376 however, do suggest that extreme drought is the most probable hypothesis for the high control

377 mortality on Plaza Sur. Another important caveat is that taxon effects are confounded with island

378 effects. With one exception, each island had a particular species or variety of Opuntia (Table 1).

379 It is possible that some of the island-based differences are actually due to slightly different

380 environmental requirements of the Opuntia taxa used in this study.

381 In conclusion, this study underlines the importance of considering the specific

382 circumstances and methodologies that affect successful restoration. Water-saving technologies

383 such as the Groasis Waterboxx ${ }^{\circledR}$ and Cocoon are promising systems for restoring species in arid

384 environments but should not be assumed to function equally well in all environments and with

385 all species. Even within one system, as in the current study, the benefits of Groasis vary

386 tremendously and likely depend on the precipitation available following plantings. It is possible

387 that species already adapted for low water conditions, such as cacti, have a much higher

388 threshold of drought at which Groasis or other water-saving technologies provide a benefit.

389 Future evaluations of these technologies should monitor precipitation to test whether there is a

390 threshold level of drought where these technologies become more effective. In some cases and

391 for some species there may be no threshold for effective use as with the Cocoon technology for

392 Opuntias. Preliminary plantings coupled with extensive environmental and experimental data

393 collection is essential before large-scale planting efforts are initiated with water-saving

394 technologies. Our work restoring reproductive Opuntia populations is still in its early stages, but 395 water-saving technologies may have a profound influence on how quickly we reach sustainable

396 levels of reproductive Opuntia populations on these islands. Field observations and unpublished

397 data suggest that Opuntias reach reproductive maturity at between 20 and 40 years of age, largely

398 dependent on the island and particular taxon (W. Tapia, J. Gibbs, \& F. Sulloway, unpublished 
399 data). A conservative estimate based on current planting survivorship is that at least $60 \%$ of

400 planted individuals (855) will reach reproductive maturity (this is based on our three-year

401 survival rate of $67 \%$, at which point yearly mortality fell to $1 \%$ ).

402 Through our experimental evaluation of restoration methodologies, the Galápagos Verde

4032050 project of the Charles Darwin Foundation presents a model for data-informed adaptive

404 management and conservation. We hope this model may inspire other restoration efforts to adopt

405 similar data-informed approaches. Continued monitoring and accounting for context-specific

406 contingencies in restoration work is essential (Cabin, 2007) and future restoration efforts should

407 continually adapt management protocols based on current results (Parma et al., 1998).

408

409 Acknowledgments

410 This is the work of the entire Galápagos Verde 2050 project team of the Charles Darwin

411 Foundation, particularly María Guerrero, Esme Plunkett, and Paúl Mayorga. Assistance and

412 advice was also provided by: Jorge Carrión, Christian Sevilla, Danny Rueda, Jeffreys Málaga,

413 Milton Chugcho, Rafael Chango, Jibson Valle, Francisco Calva, Edie Rosero and Francisco

414 Moreno from DPNG. Novarino Castillo provided valuable field assistance. Institutional support

415 was provided by DPNG (Dirección del Parque Nacional Galápagos), ECOGAL (Aeropuerto

416 Ecológico de Baltra), FAE (Fuerza Aérea Ecuatoriana), ABG (Agencia de Regulación y Control

417 de la Bioseguridad y Cuarentena para Galápagos), GAD (Gobiernos Autónomos

418 Descentralizados from Floreana and Santa Cruz). Washington Tapia, Felipe Cruz †, María del

419 Mar Trigo, and Frank Sulloway provided critical advice and encouragement. We also thank

420 Washington Tapia and Frank Sulloway for their observations and data used to estimate age of

421 maturity for Opuntias. Steve Rushton provided valuable comments on an earlier version of the

422 manuscript. Finally, we thank our editor Timothy Scheibe and three reviewers: Neftali Ochoa-

423 Alejo, Matthew Madsen, and F.B. Vincent Florens for their invaluable comments that improved

424 this manuscript. This publication is contribution number 2289 of the Charles Darwin Foundation

425 for the Galapagos Islands.

426

427 References

428 Bates, D., Mächler, M., Bolker, B. \& Walker, S. (2015). Fitting linear mixed-effects models

429 using $\{1 \mathrm{me} 4\}$. Journal of Statistical Software 67: 1-48. 
430 Black, J. (1973). Galápagos archipiélago del Ecuador. Quito, Ecuador: Imprenta Europa.

431 Boyce, S.G. (1954). The salt spray community. Ecological Society of America 24: 29-67.

432 Browne, B.R.A., Anderson, D.J., White, M.D., Johnson, M.A. (2003). Evidence for low genetic

433 divergence among Galápagos Opuntia cactus species. Noticias de Galápagos 62: 11-15.

434 Cabin, R. J. (2007). Science-driven restoration: a square grid on a round earth? Restoration 435 Ecology 15: 1-7.

436 Campbell, K. \& Donlan, C.J. (2005). Feral goat eradications on islands. Conservation Biology 437 19: $1362-1374$.

438

439

440

441

442

443

444

445

446

447

448

449

450

451

452

453

454

455

456

457

458

Carrion V., Donlan C.J., Campbell K.J., Lavoie C., Cruz F. (2011). Archipelago-Wide Island Restoration in the Gala Islands : Reducing Costs of Invasive Mammal Eradication Programs and Reinvasion Risk. PLOS One 6: 1-7.

Charles Darwin Foundation (2018). Charles Darwin Foundation meteorological database - base de datos meteorológicos de la FCD. Online data portal - portal de datos en línea: http://www.darwinfoundation.org/datazone/climate/ Last updated December 31, 2018.

Coronel, V. (2002). Distribución y re-establecimiento de Opuntia megasperma var. orientalis Howell. (Cactaceae) en punta Cevallos, Isla Española-Galápagos. Facultad de Ciencia y Tecnología, Escuela de Biología del Medio Ambiente. Universidad del Azuay, Cuenca, Azuay, Ecuador

Cruz, F., Carrion, V., Campbell, K.J., Lavoie, C. \& Donlan, C.J. (2009) Bio-economics of large scale eradication of feral goats from Santiago Island, Galápagos. Journal of Wildlife Management 73: 191-200.

Dirección del Parque Nacional Galápagos (2014). Plan de manejo de las áreas protegidas de Galápagos para el buen vivir. Dirección del Parque Nacional Galápagos, Puerto Ayora, Galápagos, Ecuador.

Dubrovsky, J.G., North, G.B. \& Nobel, P.S. (1998). Root growth, developmental changes in the apex, and hydraulic conductivity for Opuntia ficus-indica during drought. New Phytologist 138: 75-82.

Faruqi, S., Wu, A., Brolis, E., Anchondo, A., \& Batista, A. (2018). The business of planting trees: 
459

460

461

462

463

464

465

466

467

468

469

470

471

472

473

474

475

476

477

478

479

480

481

482

483

484

485

486

487

488

489

a growing investment opportunity. World Resources Institute and The Nature Conservancy. Retrieved from: https:/www.wri.org/publication/business-of-planting-trees

Gelman, A. (2008). Scaling regression inputs by dividing by two standard deviations. Statistics in Medicine 27: 2865-2873.

Gibbs, J. P., Marquez, C., \& Sterling, E. J. (2008). The role of endangered species reintroduction in ecosystem restoration: tortoise-cactus interactions on Española Island, Galápagos. Restoration Ecology 16: 88-93.

Gibbs, J.P., Sterling, E.J., Zabala, F.J. (2010). Giant tortoises as ecological engineers: A longterm quasi-experiment in the Galápagos Islands. Biotropica 42: 208-214.

Grant, B.R. \& Grant, P.R. (1981). Exploitation of Opuntia cactus by birds on the Galápagos. Oecologia 49: 179-187.

Grant P.R., Grant B.R. (1989). The slow recovery of Opuntia megasperma on Española. Noticias de Galapagos 48:13-15.

Grime, J. (1998). Benefits of plant diversity to ecosystems: immediate, filter and founder effects. Journal of Ecology 86: 902-910.

Groasis $^{\circledR}$. (2019). Waterboxx ${ }^{\circledR}$ plant cocoon. Retrieved from http://www.groasis.com/shop/consumers/waterboxx-10-pack.html. Accessed: 09-19-2019

Hamann, O. (1993). On vegetation recovery, goats and giant tortoises on Pinta Island, Galápagos, Ecuador. Biodiversity and Conservation 2: 138-151.

Helsen P., Verdyck P., Tye A., Van Dongen S. (2009). Low levels of genetic differentiation between Opuntia echios varieties on Santa Cruz (Galapagos). Plant Systematics and Evolution 279:1-10.

Hicks, D.J. \& Mauchamp, A. (1995). Size-dependent predation by feral mammals on Galápagos Opuntia. Noticias de Galápagos 53: 26-28.

Hicks, D.J. \& Mauchamp, A. (1996). Evolution and conservation biology of the Galápagos opuntias (Cactaceae). Haseltonia 4: 89-102.

Hicks, D.J. \& Mauchamp, A. (2000). Population structure and growth patterns of Opuntia echios var. gigantea along an elevational gradient in the Galápagos Islands. Biotropica 32: 235243.

Hoff, P. (2014). Groasis technology: manual de instrucciones de plantación, pp. 1-27. Jaramillo, P. (1998). Impact of human activities on the native plant life in Galápagos National 
490

491

492

493

494

495

496

497

498

499

500

501

502

503

504

505

506

507

508

509

510

511

512

513

514

515

516

517

518

519

520

Park. In Ospina, P. \& Muñóz, E. (ed.) Galápagos Report. Fundación Natura and World Wildlife Fund, Quito, pp. 50-55.

Jaramillo, P. (2015). Water-saving technology: the key to sustainable agriculture and horticulture in Galápagos to BESS Forest Club. Galápagos Verde 2050, Charles Darwin Foundation, pp. 1-12.

Jaramillo, P., Cueva, P., Jiménez, E., \& Ortiz, J. (2014). Galápagos Verde 2050. Charles Darwin Foundation, Puerto Ayora, Galápagos, Ecuador.

Jaramillo, P., Lorenz, S., Ortiz, G., Ortiz, J., Rueda, D., Gibbs, J.P., \& Tapia, W. (2015). Galápagos Verde 2050: An opportunity to restore degraded ecosystems and promote sustainable agriculture in the Archipelago. Biodiversity and Ecosystem Restoration: GNPD, GCREG, CDF, and GC. In Cayot, L., Cruz, D. \& Knab, R. (ed.). Galápagos Report 20132014, pp. 133-143.

Jaramillo, P., Tapia, W., \& Gibbs, J.P. (2017). Action plan for the ecological restoration of Baltra and Plaza Sur Islands. Charles Darwin Foundation, pp. 1-56.

Jaramillo, P., Tapia, W., \& Gibbs, J.P. (2018). Galápagos Verde 2050: restauración ecológica de ecosistemas degradados y agricultura sostenible utilizando tecnologías ahorradoras de agua. In prep. Fundación Charles Darwin, Puerto Ayora, Isla Santa Cruz.

Jaramillo, P., Tapia, W., \& Tye, A. (2018). Opuntia megasperma var. orientalis Howell. In FCD \& WWF-Ecuador (ed.) Atlas de Galápagos, Ecuador. Quito, Ecuador: FCD \& WWF Ecuador, pp. 58-59.

Jaramillo, P. (2019). Manual de procesos y protocolos del proyecto Galápagos Verde 2050. In prep. Fundación Charles Darwin, Puerto Ayora, Galápagos, Ecuador.

Johnson, M.P., Raven, P.H. (1973). Species number and endemism: The Galápagos archipelago revisited. Science 179: 893-895.

Kulkarni, S. (2011). Innovative technologies for water saving in irrigated agriculture. International Journal of Water Resources and Arid Environments 1: 226-231.

Kuznetsova, A., Brockhoff, P.B. \& Christensen, R.H.B. (2017). lmerTest Package: tests in linear mixed effects models. Journal of Statistical Software 82: 1-26.

Land Life Company (2015). Benefits of the COCOON technology. Retrieved from https://landlifecompany.com 
521 Liu M., Li, Z., Ren W (2014) Research on the effect of waterboxx technology on Haloxylon 522 ammodendron afforestation in arid and semiarid areas. Advanced Science, Engineering and 523 Medicine 6: 236-239.

524 Lomolino, M.V. \& Weiser, M.D. (2001). Towards a more general species-area relationship 525 diversity on all islands, great and small. Journal of Biogeography 28: 431-445.

526 Mauchamp A., Aldaz I., Ortiz E., Valdebenito H. (1998). Threatened species, a re-evaluation of 527 the status of eight endemic plants of the Galapagos. Biodiversity and Conservation 7:97$528 \quad 107$.

529 Menendez, Y., \& Jaramillo, P. (2015). Aplicación Android y plataforma virtual del proyecto $530 \quad$ Galápagos Verde 2050.

531 Myers, N., Mittermeier, R.A., Mittermeier, C.G., da Fonseca, G.A.B., Kent, J. (2000).

532 Biodiversity hotspots for conservation priorities. Nature 403: 853-858.

533 Parma, A.M. \& NCEAS Working Group on Population Management (1998). What can adaptive 534 535 management do for our fish, forests, food, and biodiversity? Integrative Biology: Issues, News, and Reviews 1: 16-26.

Peyrusson, F. (2018). Effect of hydrogel on the plants growth. Université Catholique Louvain, Belgium.

Pinheiro, J.C. \& Bates, D.M. (2000). Mixed-effects models in S and S-PLUS. Springer. New 539 York.

R Core Team (2017). R a language and environment for statistical computing. R Foundation for Statistical Computing, Vienna, Austria. URL https://www.R-project.org/.

542 Racine, C.H., \& Downhower, J. F. (1974). Vegetative and reproductive strategies of Opuntia (Cactaceae) in the Galápagos Islands. Biotropica 6: 175-186.

Rajakaruna, N., Pope, N., Perez-Orozco, J., \& Harris, T.B. (2009). Ornithocoprophilous plants of Mount Desert Rock, a remote bird-nesting island in the Gulf of Maine, USA. Rhodora 111: 417-448.

Restrepo, A., Colinvaux, P., Bush, M., Correa-Metrio, A., Conroy, J., Gardener, M.R., Jaramillo, P., Steinitz-Kannan, M., Overpeck, J. (2012). Impacts of climate variability and human colonization on the vegetation of the Galápagos Islands. Ecology 93: 1853-1866.

5: $48-51$.


552 Snell, H.L., Snell, H.M., \& Stone, P. (1994). Accelerated mortality of Opuntia on Isla Plaza Sur: another threat from an introduced vertebrate? Noticias de Galápagos 53: 19-20.

554 Snell, H. \& Rea, S. (1999). The 1997-98 El Niño in Galápagos: can 34 years of data estimate 120 years of pattern? Noticias de Galápagos: 11-20.

556

557

558

559

560

561

562

563

564

565

566 567

568

569

570

Snyman, H.A. (2005). A case study on in situ rooting profiles and water-use efficiency of cactus pears, Opuntia ficus-indica and O. robusta. Journal of the Professional Association for Cactus Development: 1-21.

Stryhn, H. \& Christensen, J. (2003). Confidence intervals by the profile likelihood method, with applications in veterinary epidemiology. Proceedings of the 10th International Symposium on Veterinary Epidemiology and Economics: 208-211.

Sulloway, F.J. \& Noonan, K. (2015). Opuntia cactus loss in the Galápagos Islands, 1957-2014 (Pérdida de cactus Opuntia en las Islas Galápagos, 1957-2014). Technical Report, 1-30.

Sulloway, F.J., Noonan, K.M., Noonan, D.A. \& Olila, K.J. (2013). Documenting ecological changes in the Galápagos since Darwin's visit. Project Proposal, 1-32.

Trueman, M. \& D’Ozouville, N. (2010). Characterizing the Galápagos terrestrial climate in the face of global climate change. Galápagos Research 67: 26-37.

Tye, A. (2007). La flora endémica de Galápagos: aumentan las especies amenazadas. In: FCD, PNG, INGALA, editors. Informe Galápagos 2006-2007. Puerto Ayora, Galápagos, Ecuador. p 101-107.

PeerJ reviewing PDF | (2019:06:38957:1:2:NEW 22 Oct 2019) 


\section{Table $\mathbf{1}$ (on next page)}

Total number of Opuntia spp. individuals planted by island by Galápagos Verde 2050 (2013-2018).

Numbers in parentheses '( )' are the number of individuals used in the current study analysis (Figures $3 \& 4$ ). 
1 Table 1. Total number of Opuntia spp. individuals planted by island by Galápagos Verde

22050 (2013-2018). Numbers in parentheses '()' are the number of individuals used in the current

3 study analysis (Figures 4 \& 5).

\begin{tabular}{|c|c|c|c|c|c|c|}
\hline Species & Baltra & Española & Floreana & $\begin{array}{c}\text { Plaza } \\
\text { Sur }\end{array}$ & $\begin{array}{c}\text { San } \\
\text { Cristóbal }\end{array}$ & $\begin{array}{l}\text { Santa } \\
\text { Cruz }\end{array}$ \\
\hline Opuntia echios var. echios & $400(349)$ & - & - & $737(601)$ & - & - \\
\hline Opuntia echios var. gigantea & - & - & - & - & - & $68(60)$ \\
\hline Opuntia megasperma var. megasperma & - & 一 & $20(19)$ & - & $4(0)$ & - \\
\hline Opuntia megasperma var. orientalis & - & $196(0)$ & - & - & - & - \\
\hline
\end{tabular}




\section{Table 2 (on next page)}

List of all sites of Galápagos Verde 2050 Opuntia spp. restoration and number of Opuntia spp. individuals planted (2013-2018).

Numbers in parentheses '()' represent the percent of individuals that have survived through 2018. 
1 Table 2. List of all sites of Galápagos Verde 2050 Opuntia spp. restoration and number of

2 Opuntia spp. individuals planted (2013-2018). Numbers in parenthases '()' represent the

3 percent of individuals that have survived through 2018.

\begin{tabular}{|c|c|c|c|c|}
\hline Island & Site Name & \# Planted & UTM East $^{1}$ & UTM North $^{1}$ \\
\hline \multirow[t]{4}{*}{ Baltra $(70 \%)$} & Antiguo basurero & $158(69 \%)$ & 804668 & 9950436 \\
\hline & Casa de piedra & $125(74 \%)$ & 802460 & 9948203 \\
\hline & Jardín ecológico Aeropuerto & $1(100 \%)$ & 804100 & 9950795 \\
\hline & Parque Eólico & $116(68 \%)$ & 803992 & 9950909 \\
\hline Española (79\%) & Las Tunas & $196(79 \%)$ & $199759^{*}$ & $9849118^{*}$ \\
\hline \multirow[t]{5}{*}{ Floreana $(40 \%)$} & Botadero de basura & $3(33 \%)$ & 781054 & 9858587 \\
\hline & Cementerio & $7(29 \%)$ & 780322 & 9858645 \\
\hline & Escuela Amazonas & $5(40 \%)$ & 779594 & 9858865 \\
\hline & Gobierno Parroquial Floreana & $1(0 \%)$ & 779530 & 9859029 \\
\hline & $\begin{array}{l}\text { Oficina Técnica Parque } \\
\text { Nacional Galápagos }\end{array}$ & $4(75 \%)$ & 779531 & 9859244 \\
\hline \multirow[t]{3}{*}{ Plaza Sur (61\%) } & Centro & $254(62 \%)$ & 815800 & 9935365 \\
\hline & Los Lobos Este & $253(47 \%)$ & 815936 & 815936 \\
\hline & Oeste Cerro Colorado & $230(76 \%)$ & 815304 & 9935602 \\
\hline San Cristóbal (100\%) & CA Jacinto Gordillo & $4(100 \%)$ & $209711^{*}$ & $9900150^{*}$ \\
\hline \multirow[t]{4}{*}{ Santa Cruz (65\%) } & Colegio Nacional Galápagos & $2(50 \%)$ & 798782 & 9918296 \\
\hline & Espacio Verde ABG & $8(88 \%)$ & 797864 & 9918887 \\
\hline & Fundación Charles Darwin & $51(67 \%)$ & 800106 & 9917856 \\
\hline & $\begin{array}{l}\text { Oficina Técnica Parque } \\
\text { Nacional Galápagos }\end{array}$ & $7(29 \%)$ & 799811 & 9917994 \\
\hline
\end{tabular}

$4 \quad{ }^{1}$ UTM Zone $=15 \mathrm{M}$, datum $=$ WGS84

$5 *$ UTM Zone $=16 \mathrm{M}$ 
Figure 1

Map of the Galápagos Islands, Ecuador.

Islands included in the current study are darkened and labeled in bold.

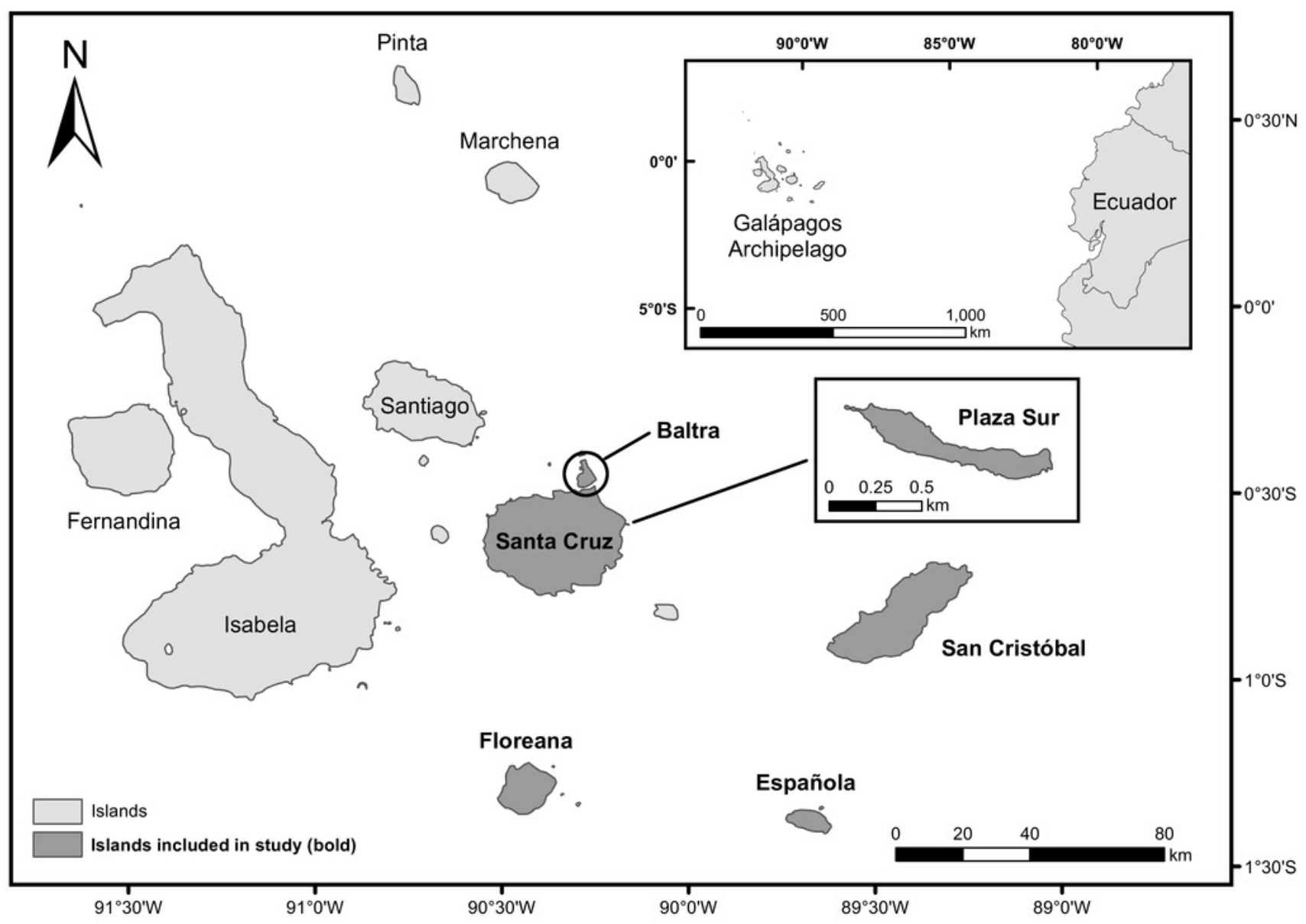




\section{Figure 2}

Total Opuntia spp. restoration from 2013 to 2018 across Baltra, Española, Floreana, Plaza Sur, San Cristóbal, and Santa Cruz islands.

Values above bars indicate total surviving individuals by the end of each year ( $y$-axis values). Values at the bottom indicate the total number of individuals planted each year.

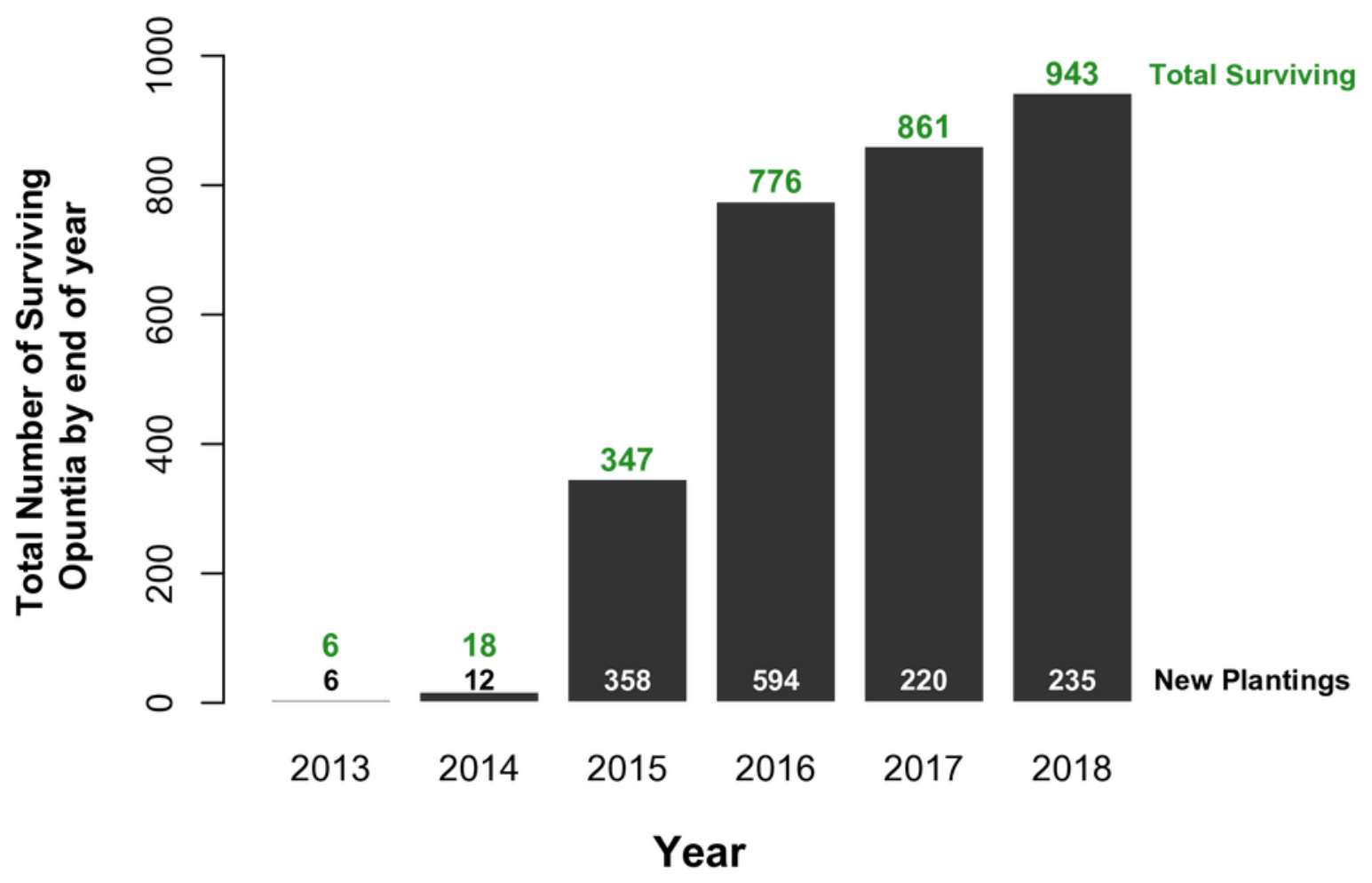




\section{Figure 3}

State of each planted Opuntia individual by the end of 2018 within each island.
A. Plaza Sur; B. Floreana; C. Baltra; D. Santa Cruz. "N" indicates the total number of individuals within each treatment on each island. Plant state categories ("good", "regular", "poor", and "dead") refer to the subjective observation of the physical state of the plant. "Good" plants are fully green with no signs of desiccation or browning in the cladodes, while "poor" plants appear desiccated and browning, and likely to die soon. The figure is based on the last noted observation of each plant at the end of 2018 and based on only those data used in the analysis. 

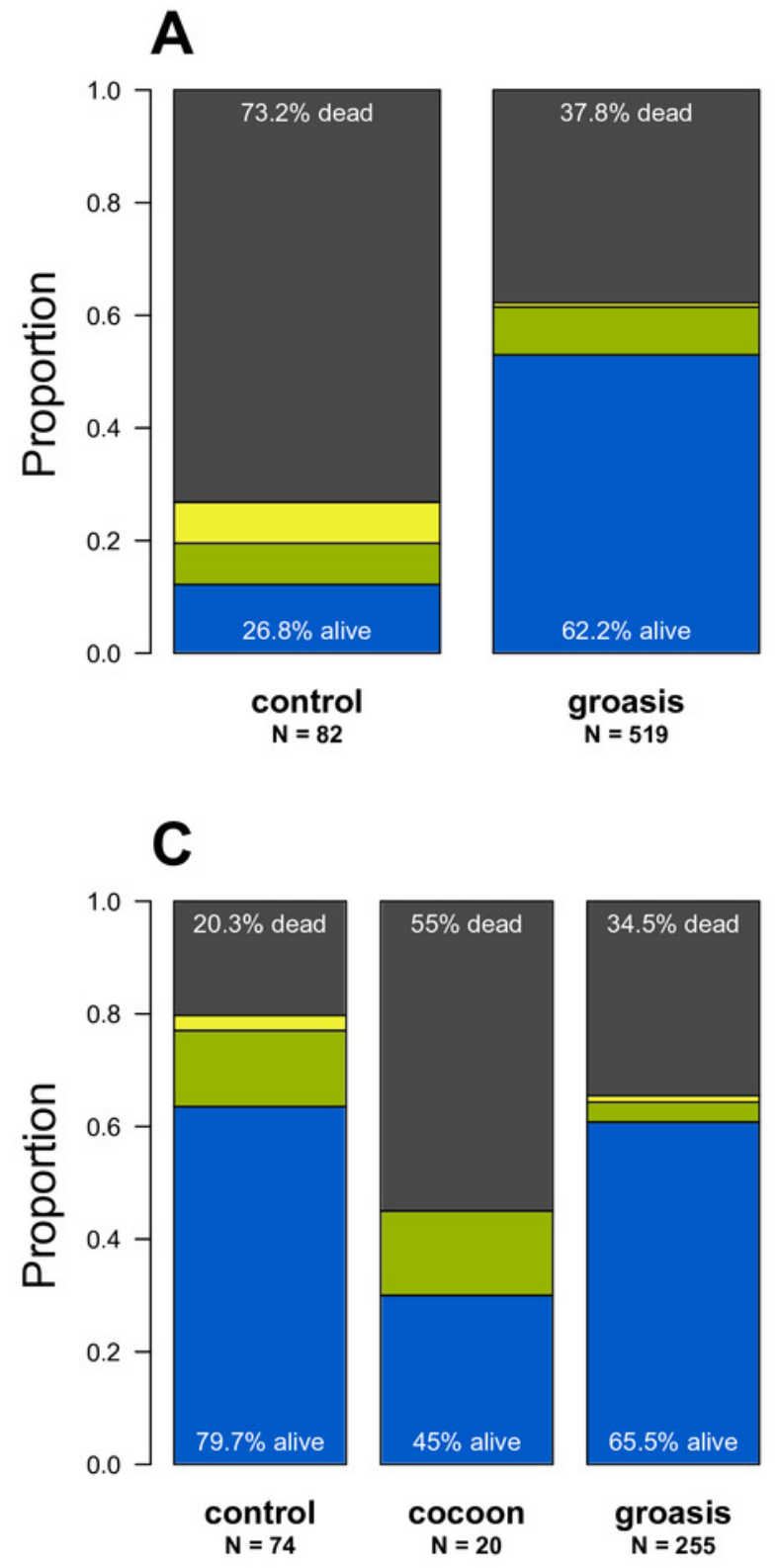

B

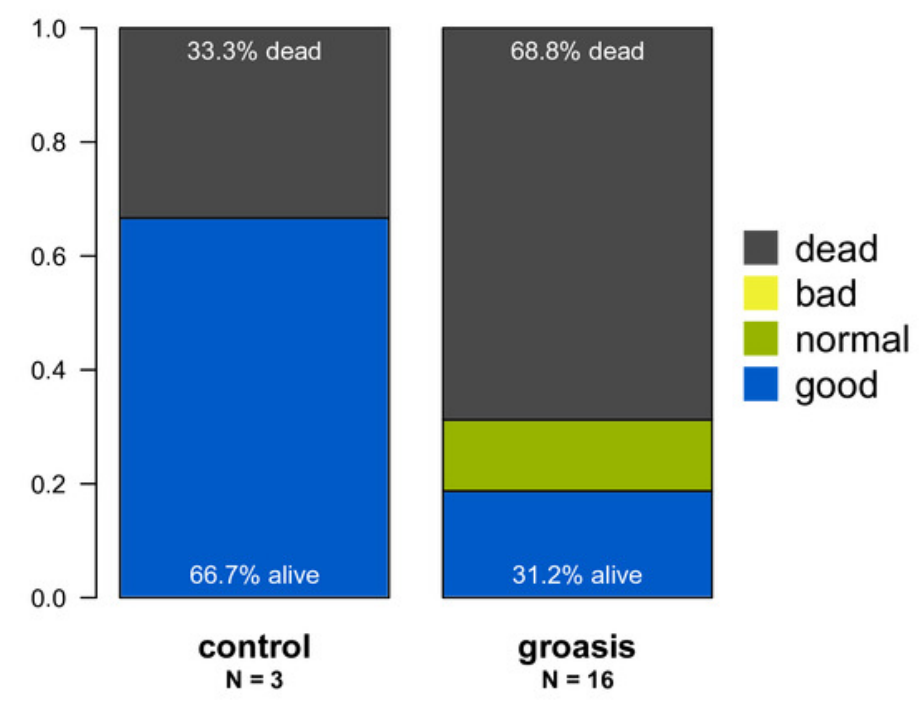

D

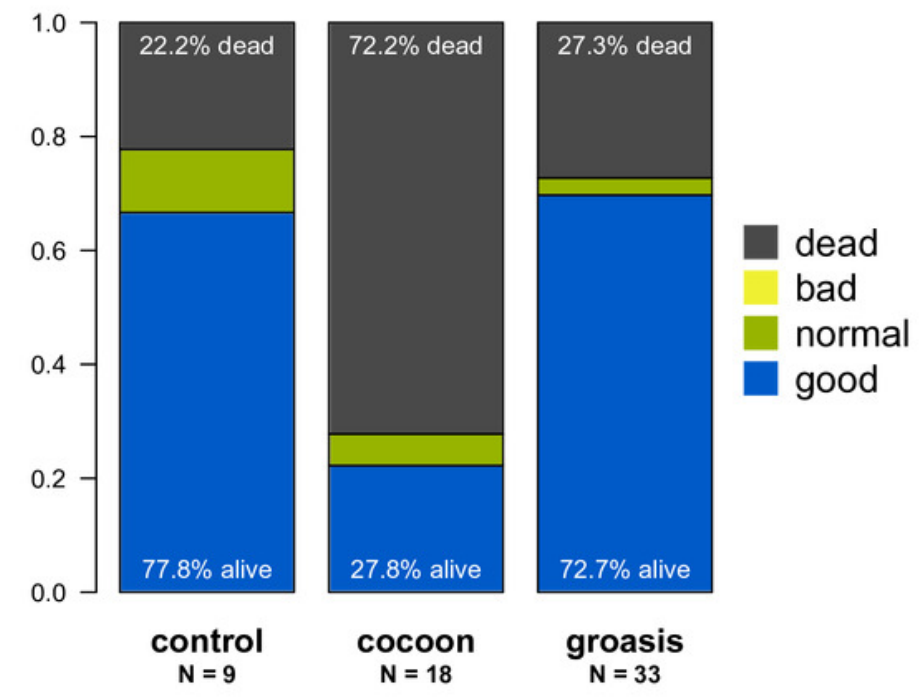




\section{Figure 4}

Plots of the relative effect of variable parameters on two-year survival and growth rate of planted Opuntia individuals.

A. all islands two-year survival; B. all islands growth rate; C. Plaza Sur island two-year survival; D. Plaza Sur island growth rate; E. all islands excluding Plaza Sur two-year survival; and F. all islands excluding Plaza Sur growth rate. Each point represents coefficient estimate +/- 95\% confidence intervals. P-values are generated based on the Satterthwaite method for growth rate models and the Wald statistic for survival models $(* P<0.05$, **P $<0.01, * * * P<$ 0.001). Values for two-year survival models are converted to odds ratio by exponentiating coefficients and subtracting one. Analyses are based on data from Baltra, Floreana, Plaza Sur, and Santa Cruz islands. Littoral zone values in A. and C. fall outside the scale of those boxes, so confidence intervals are presented as text. 

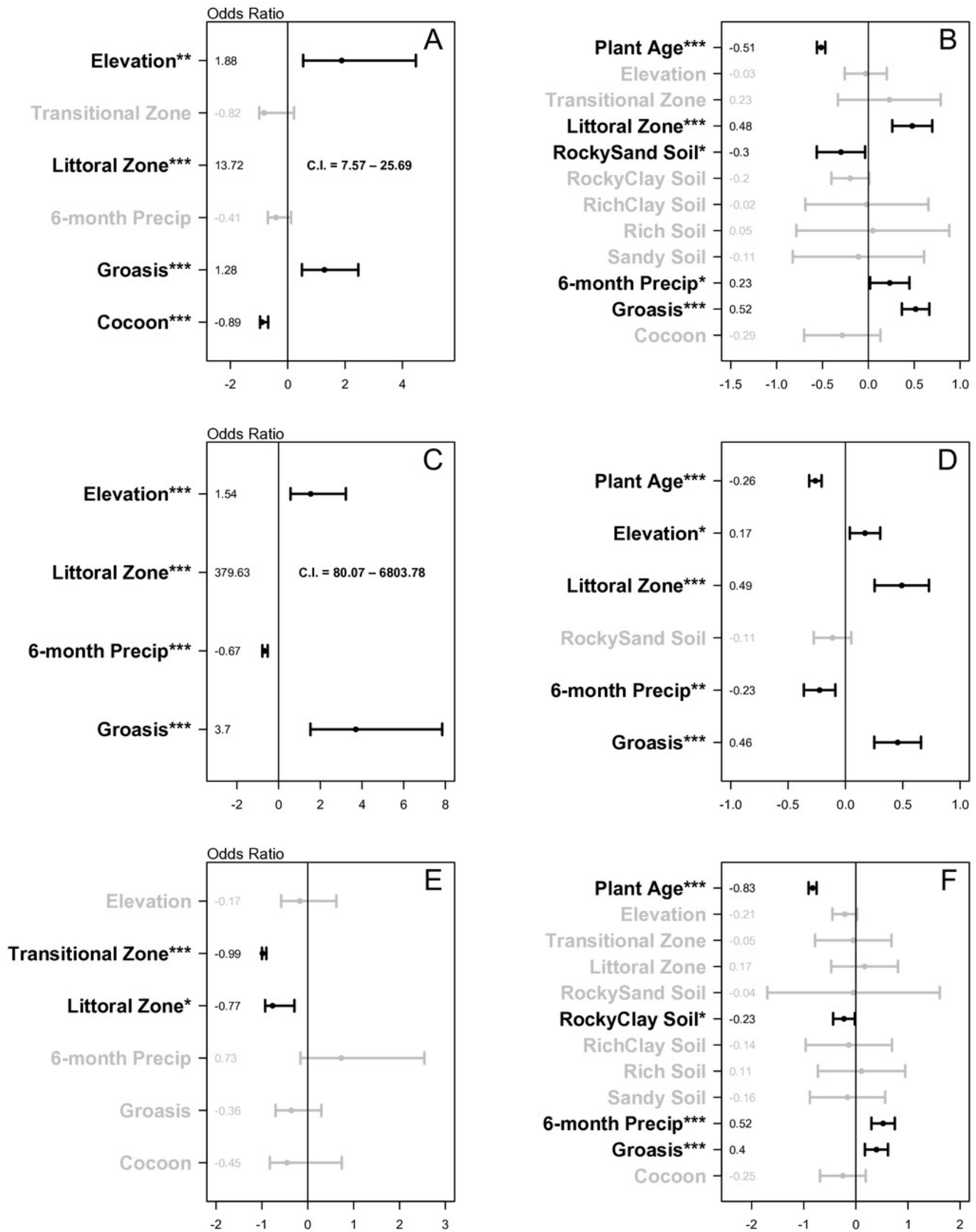